\title{
EFEITOS DO TRATAMENTO TÉRMICO EM TECIDO DE POLI (TEREFTALATO DE ETILENO) - PET
}

\author{
J. G. de CARVALHO ${ }^{1}$ e J. SINÉZIO C. C. ${ }^{2}$ \\ ${ }^{1} 3 \mathrm{M}$ do Brasil \\ ${ }^{2}$ UNICAMP - Faculdade de Engenharia Química, Departamento de Engenharia de Materiais e \\ Bioprocessos. \\ E-mail para contato: carvalhojos@hotmail.com, sinezio@feq.unicamp.br,
}

\begin{abstract}
RESUMO - Dentre os materiais utilizados na indústria têxtil as fibras do polímero poli (tereftalato de etileno) (PET) representa mais de 50\%, tanto em vestuário quanto em decoração e dentre as exigências do consumidor esta a estabilidade dimensional do tecido. Esta propriedade física é alcançada pelo processo de termofixação, o qual tem por base o adequado tratamento térmico, encontrando-se uma combinação ideal de temperatura e tempo, principalmente na etapa de beneficiamento do tecido. Devido à importância deste processo e da quantidade reduzida de trabalhos científicos, este trabalho visa colaborar no entendimento das propriedades físicas (encolhimento, hidrofilidade, alongamento e ruptura) de tecidos contendo fibras de PET. Recortaram-se amostras de tecido plano (100\% de fibras PET) e após serem submetidas a tratamento térmico entre 120 e $220{ }^{\circ} \mathrm{C}$ e tempos de 30 a 120 s avaliaram-se as características físicas através de ensaios de acordo com respectivas normas técnicas. Os resultados mostram que: quanto maior o valor da temperatura maior é o encolhimento, chegando a $12 \%$ para temperatura de $220{ }^{\circ} \mathrm{C}$; maior índice de alongamento (20\%) ocorreu para temperatura de $220{ }^{\circ} \mathrm{C}$; a hidrofilidade diminui quanto maior a temperatura e o tempo de tratamento não altera essas propriedades físicas.
\end{abstract}

\section{INTRODUÇÃO}

As fibras sintéticas são utilizadas nas indústrias para obter diferentes produtos, como por exemplo: vestuário, estofamento para automóveis, fabricação de entretelas, material hospitalar e de limpeza. Essas fibras representam uma produção de cerca de 350 mil toneladas/ano, ABRAFAS (2013). Entre as fibras sintéticas para aplicação no segmento têxtil, as do polímero Poli (tereftalato de etileno) - PET, são as mais utilizadas, Scheirs (2003), ABRAFAS (2013).

Durante a fabricação e consumo de tecidos feitos com fibras do polímero PET, uma propriedade fundamental é a estabilidade dimensional que é obtida por meio do tratamento térmico que na indústria têxtil é conhecido como termofixação. 


\section{9 a 22 de outubro de 2014 \\ Florianópolis/SC}

O processo de termofixação promove alterações em propriedades do tecido, como por exemplo, hidrofilidade, estabilidade dimensional e alongamento. Essas propriedades são importantes para os processos de beneficiamento do tecido, fazendo-se necessário o entendimento do impacto causado pelo processo de termofixação nas referidas propriedades.

\section{FIBRAS DE POLIÉSTER}

As normas ISO 2076 e a Diretiva UE definem o nome genérico poliéster (PES) como "fibra composta de macromoléculas lineares cuja cadeia contém um mínimo de $85 \%$ em massa de um diol e do ácido tereftálico", Guillen (2003).

O PET é o mais importante membro da família dos poliésteres. Foi desenvolvido por dois químicos britânicos Whinfield e Dickson em 1941 e é classificado quimicamente como um polímero termoplástico, ou seja, funde por aquecimento e solidifica por resfriamento. Pode ser apresentado no estado amorfo (transparente), parcialmente cristalino e orientado (translúcido) e altamente cristalino (opaco), Scheirs (2003), Ludewig (1964). Este polímero é obtido pela polimerização por condensação do ácido tereftálico (ou tereftalato de dimetila) com o etileno glicol, Odian (1991).

Das fibras sintéticas produzidas em 2012 no Brasil, aproximadamente, 77\% foram de poliéster, $16 \%$ náilon, $4 \%$ acrílico e 3\% elastômeros, ABRAFAS (2013).

O PET usado na produção de fibras têxteis apresenta grau de polimerização em torno de 100, comprimento de cadeia em torno de $100 \mathrm{~nm}$ e peso molecular aproximadamente entre 15000 e 20000, Araujo (1984), Kim (2006). Essas fibras são compostas de regiões cristalinas, semicristalinas e amorfas. A massa específica do PET amorfo é $1,33 \mathrm{~g} / \mathrm{cm}^{3}$, mas a orientação e o aumento de cristalinidade fazem com que essa massa varie entre 1,38 e $1,40 \mathrm{~g} / \mathrm{cm}^{3}$. A temperatura de transição vítrea (tg) está entre 65 e $75^{\circ} \mathrm{C}$, e a temperatura de fusão (tm) entre $\sim 265$ e $285^{\circ} \mathrm{C}$, Kim (2006).

\section{ESTABILIDADE DIMENSIONAL}

Na produção dos tecidos e nos seus diferentes processos de beneficiamento, surgem alterações dimensionais devido a ações mecânicas, térmicas e químicas que, na maioria dos casos, se manifestam posteriormente, por um encurtamento na direção longitudinal. Este fenômeno é geralmente, referido como encolhimento. $\mathrm{O}$ valor do encolhimento de um tecido depende principalmente da influência do material e das condições de produção, como o meio em que o tecido é beneficiado (água, vapor, calor, seco, etc.), a temperatura e os esforços mecânicos, aos quais ele é submetido, Geocities (2014).

O mecanismo do encolhimento pode, parcialmente, ser explicado pelo alívio de tensões internas introduzidas nos fios durante os processos de fiação e tecelagem. Pela atuação de água, ar quente ou vapor, as tensões latentes podem ser aliviadas. Os tecidos tendem então a atingir um estado estável em suas dimensões, e o tempo necessário para isto vai depender do tipo da fibra, do tipo e condições de tratamentos aplicados nos tratamentos hidrotérmicos, o encolhimento não é linear com o aumento da temperatura. Já no tratamento em ar quente, há certa linearidade na relação entre a temperatura e o 
encolhimento, Geocities (2014).

Assim nota-se claramente a importância do conhecimento sobre tratamentos térmicos e processos de termofixação, pois estes são fundamentais para estabilidade e propriedades físicoquímicas das fibras têxteis.

\section{TERMOFIXAÇÃO}

O processo de termofixação é baseado no aquecimento das fibras dentro de uma faixa específica de temperatura cujo limite superior é a temperatura de fusão e o limite inferior é a temperatura de transição vítrea (necessária para quebrar as ligações secundárias) e os principais resultados obtidos pelo processo de termofixação são: homogeneização da estrutura da fibra, eliminação de tensão interna da fibra resultando em redução do encolhimento durante processos de beneficiamento subsequentes e uso final, aumento da estabilidade dimensional e redução do enrolamento das laterais de tecidos planos e malhas, Rouette (2001).

As mudanças causadas pela termofixação não são apenas mecânicas, mas também nas propriedades de tingimento das fibras sintéticas. A temperatura selecionada determina as propriedades de tingimento subsequentes como segue: Com o aumento da temperatura (no caso do poliéster, acima de $200{ }^{\circ} \mathrm{C}$ ) a proporção de regiões cristalinas diminui porque os cristalitos instáveis fundem e a massa polimérica recristaliza parcialmente posteriormente. Quanto maior a proporção de regiões não cristalinas depois da termofixação, que também é influenciada pela taxa de resfriamento (resfriamento rápido reduz a recristalização), melhores serão as propriedades de tingimento posterior, Rouette (2001).

A termofixação dos tecidos de poliéster pode ser feita em temperaturas nominais compreendidas entre $160{ }^{\circ} \mathrm{C}$ e $220^{\circ} \mathrm{C}$ e tempos de 30 a 120 segundos, Rouette (2001).

Giordano e Sinézio (2006) estudaram a influência dos parâmetros tempo e temperatura de termofixação na estabilidade dimensional do tecido de poliéster. Eles demonstraram que temperaturas de termofixação acima de $170{ }^{\circ} \mathrm{C}$ conferem ao tecido boa estabilidade dimensional, ou seja, o tecido termofixado em tais temperaturas, não se encolhe quando submetido a tratamentos posteriores ou durante o uso.

Garcém et al. (2007) estudaram a influência da temperatura de termofixação do poliéster na absorção e velocidade de difusão de corantes dispersos. Segundo esses autores temperaturas de termofixação, entre 190 e $200{ }^{\circ} \mathrm{C}$, aumenta a absorção de algumas classes de corante disperso pelo substrato têxtil e a difusão do corante não apresenta uma relação linear com a temperatura de termofixação, sendo que tipos de corantes dispersos analisados apresentaram comportamentos diferentes uns dos outros.

Rao et al. (2008) observaram que variando a temperatura de termofixação de filmes de PET é possível variar sistematicamente a morfologia cristalina desse material. 


\section{MATERIAIS E MÉTODOS}

\subsection{Materiais}

- Tecido $100 \%$ poliéster (Urdume 36 fios/cm 30 tex, trama 24 fios/cm 80 tex, 350 g/m²);

- Dinamômetro, Rama, Balança, Corante, Vidrarias.

\subsection{Métodos}

\subsection{Ensaio de alongamento e tração}

Recortou-se amostras de tecido de poliéster e preparou-se as mesmas para o ensaio de resistência à tração e alongamento nos sentidos da trama e do urdume, segundo a norma NBR 11912. Submeteu-se as amostras ao processo de termofixação em diferentes condições de tempo e temperatura. Submeteu-se amostras termofixadas e sem termofixar ao ensaio de alongamento ruptura em dinamômetro como descrito na norma NBR 11912 com o objetivo de verificar a influência do tempo e temperatura de termofixação nas propriedades de alongamento e força de ruptura do tecido de poliéster.

\subsection{Termofixação e encolhimento}

Termofixou-se amostras de tecido de poliéster nas seguintes temperaturas: 120, 160, 180, 200 e $220{ }^{\circ} \mathrm{C}$ por $30,60,90$ e 200 segundos. Utilizou-se rama de laboratório com controles automáticos de tempo e temperatura.

Com o objetivo de verificar a influência da temperatura e tempo de termofixação no encolhimento do tecido de poliéster, mediu-se as dimensões das amostras preparadas para ensaio de alongamento ruptura antes e depois da termofixação e em seguida calculou-se o percentual de encolhimento das mesmas.

\subsection{Hidrofilidade}

Mediu-se a hidrofilidade do tecido através da análise de absorção de gota de solução de corante depositada na superfície do tecido, de acordo com a norma NBR 13000.

\section{RESULTADOS E DISCUSSÃO}

\subsection{Encolhimento}

A figura 1 apresenta os resultados das amostras do tecido de poliéster submetidas aos ensaios de encolhimento em função da temperatura de termofixação para urdume (Fig. 1A) e trama (Fig. 1B). Observa-se nessa figura, que o processo de termofixação promove encolhimento do tecido de poliéster no sentido da trama e do urdume, e esse encolhimento varia com tempo e temperatura de termofixação. Pode-se observar que o encolhimento aumenta com o aumento da temperatura do 
processo. Observa-se que para temperatura de $120{ }^{\circ} \mathrm{C}$ o encolhimento é pequeno em comparação às demais temperaturas e atinge seu maior valor na temperatura de $220{ }^{\circ} \mathrm{C}$, onde observa-se encolhimento $\sim 12 \%$ no sentido da trama e $\sim 10 \%$ no sentido do urdume. Observa-se também que o tempo de processo praticamente não influencia a propriedade de encolhimento do tecido de poliéster.

A

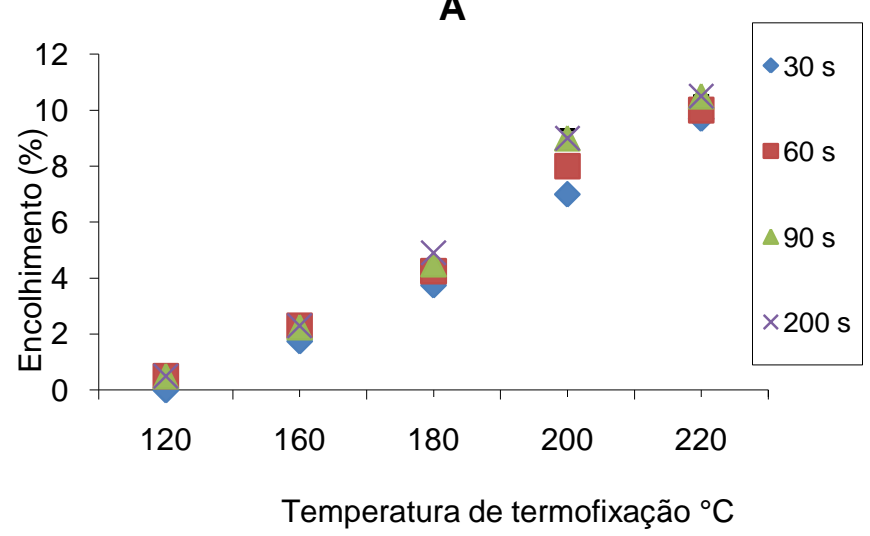

B

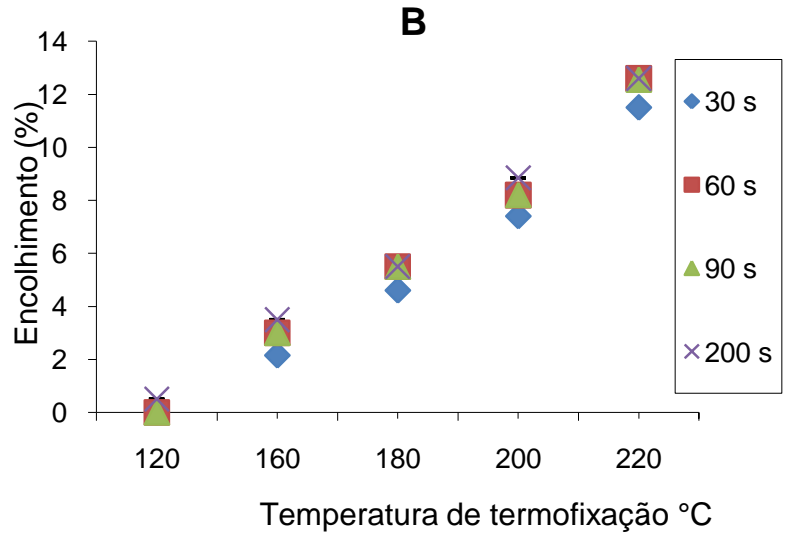

Figura 1: Encolhimento (\%) em função da temperatura de termofixação para amostras de tecido de poliéster no sentido do urdume (A) e no sentido da trama (B) para tempos de termofixação de $30,60,90$ e 200 s.

O comportamento observado na figura 4 para o tecido de poliéster pode ser explicado da seguinte forma: o estado físico-mecânico borrachoso, para polímeros semicristalinos como o PET, acontece em temperaturas entre Tg e Tm que no caso do PET são $\sim 65$ e $\sim 265{ }^{\circ} \mathrm{C}$ respectivamente. Nessa faixa de temperatura o PET ao ser aquecido tende a encolher. Isso acontece porque as cadeias poliméricas da fibra que foram estiradas durante o processo de fabricação contraem com o aumento da temperatura. Essa contração acontece porque para aumentar a entropia do sistema, é necessário aumentar o número de conformações possíveis da cadeia, que pode ser conseguido com a aproximação das suas duas pontas. Esse comportamento se repete para todas as cadeias gerando o efeito macroscópico de contração ou encolhimento.

\subsection{Alongamento e Ruptura}

A figura 2 apresenta os resultados das amostras do tecido de poliéster submetidas aos ensaios de alongamento em função da temperatura de termofixação para trama (Fig. 2A) e urdume (Fig. 2B). Observa-se que o processo de termofixação promove o aumento do alongamento do tecido de poliéster nos sentidos da trama e do urdume, e esse aumento varia com a temperatura de termofixação, ou seja, aumentando a temperatura de termofixação aumenta-se também o percentual de alongamento do tecido que atinge valor de $\sim 20 \%$ para a temperatura de $220{ }^{\circ} \mathrm{C}$. Observa-se também que o tempo de termofixação não promove alterações consideráveis no percentual de alongamento do tecido de poliéster nos sentidos da trama e do urdume. 
A
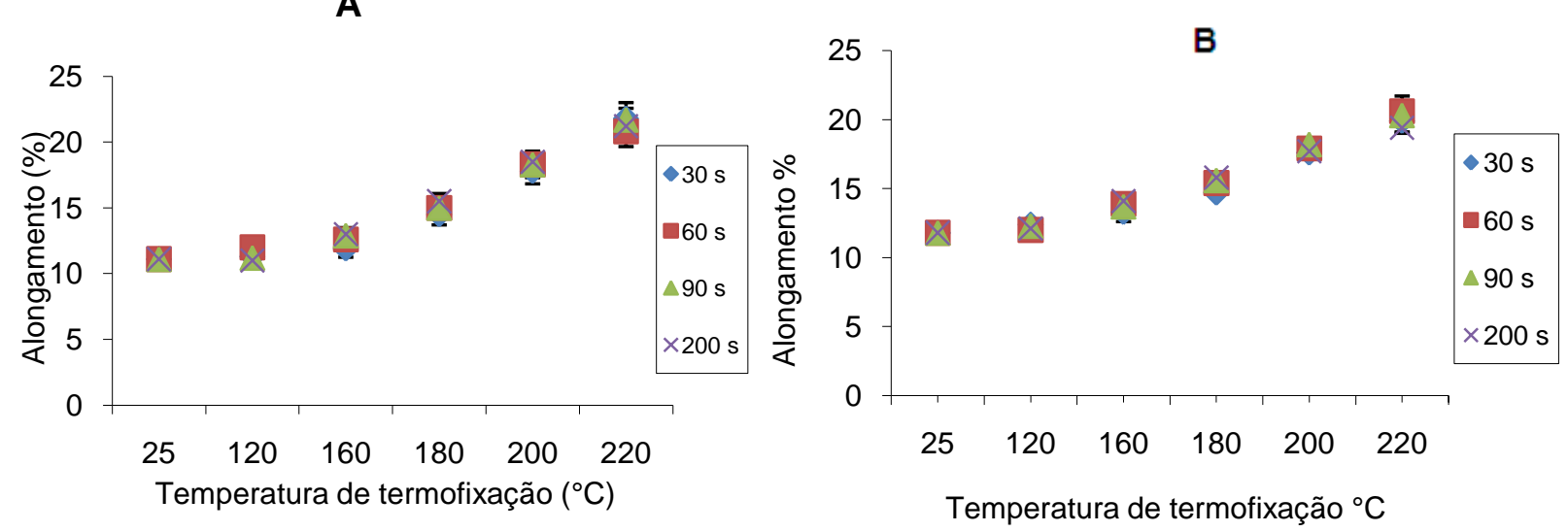

Figura 2: Alongamento (\%) em função da temperatura de termofixação para amostras de tecido de poliéster no sentido da trama (A) e no sentido do urdume (B) para os tempos de termofixação $30,60,90$ e 200 s.

Esse comportamento está associado ao fato de as cadeias poliméricas terem se encolhido durante a termofixação, tornando possível um alongamento maior quando submetidas a uma força de tração. Isso pode ser visto ao comparar as figuras 1 e 2, onde se observa que as amostras que tiveram maior encolhimento na termofixação, foram as mesmas que alcançaram maior alongamento nos ensaios de alongamento e ruptura.

A figura 3 apresenta os resultados das amostras do tecido de poliéster termofixadas e não termofixadas submetidas ao ensaio de alongamento em função do tempo de tratamento corona.

A

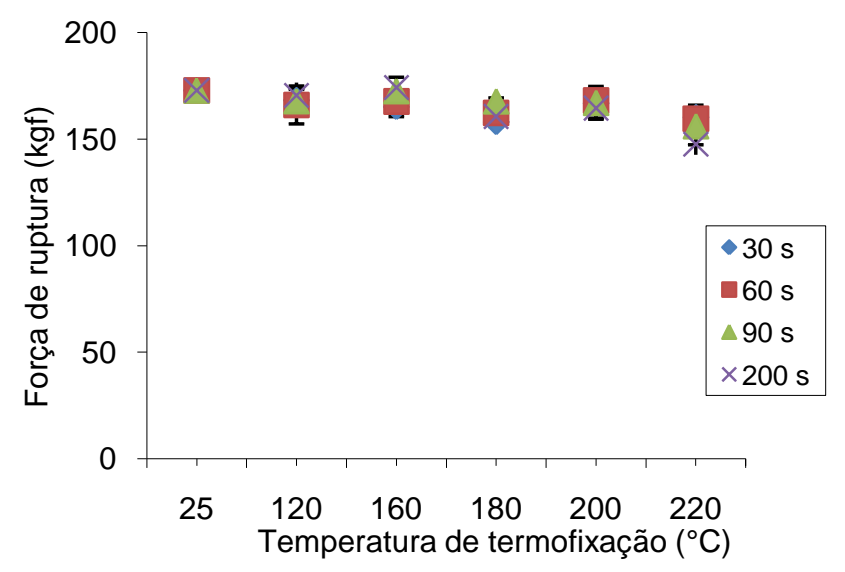

B

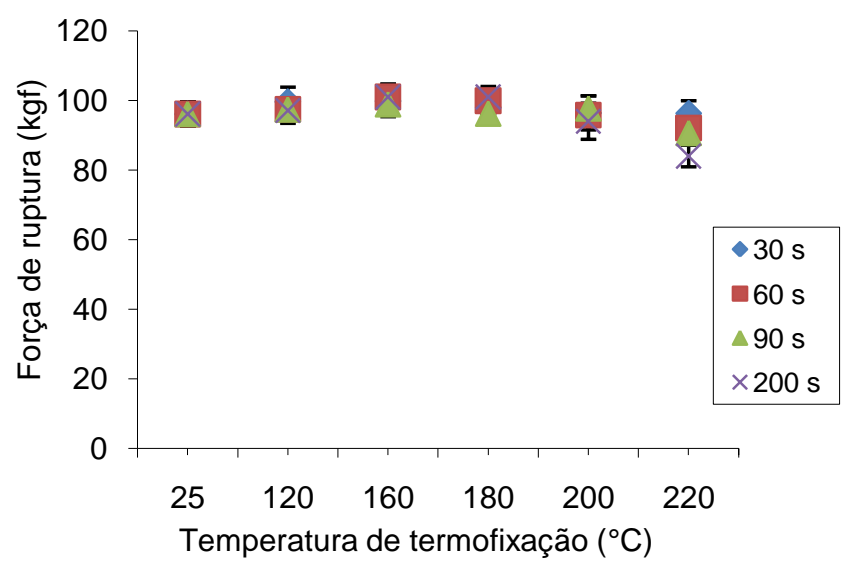

Figura 3: Força de ruptura (kgf) em função da temperatura de termofixação para amostras de tecido de poliéster no sentido da trama (A) e no sentido do urdume (B) para os tempos de termofixação 30, 60, 90 e 200s. 
Observa-se na figura 3 que o processo de termofixação pouco influencia na força de ruptura das amostras de poliéster no sentido da trama e do urdume. Segundo Odian (1991), o comportamento mecânico dos polímeros está associado ao grau de cristalinidade, quantidade de ligações cruzadas, e aos valores de Tg e Tm. Acredita-se que o processo de termofixação, nas condições praticadas nesse trabalho, não proporciona mudanças significativas nessas propriedades e isso explicaria a pouca influência do processo termofixação na força de ruptura do tecido de poliéster, como se observa na figura 3.

\subsection{Hidrofilidade}

A figura 4 apresenta os resultados das amostras de tecido de poliéster submetidas ao ensaio de hidrofilidade em função da temperatura de termofixação.

Observa-se na figura 4 que o processo de termofixação promove a diminuição da hidrofilidade do tecido de poliéster, ou seja, as amostras termofixadas apresentam tempos maiores para absorção da gota de solução de corante. Pode-se observar que a hidrofilidade diminui com o aumento da temperatura e do tempo de termofixação. Não foi possível obter resultados de hidrofilidade para amostras do tecido termofixado na temperatura de $220{ }^{\circ} \mathrm{C}$, ou seja, a gota de solução evaporava antes de ser absorvida pelo tecido

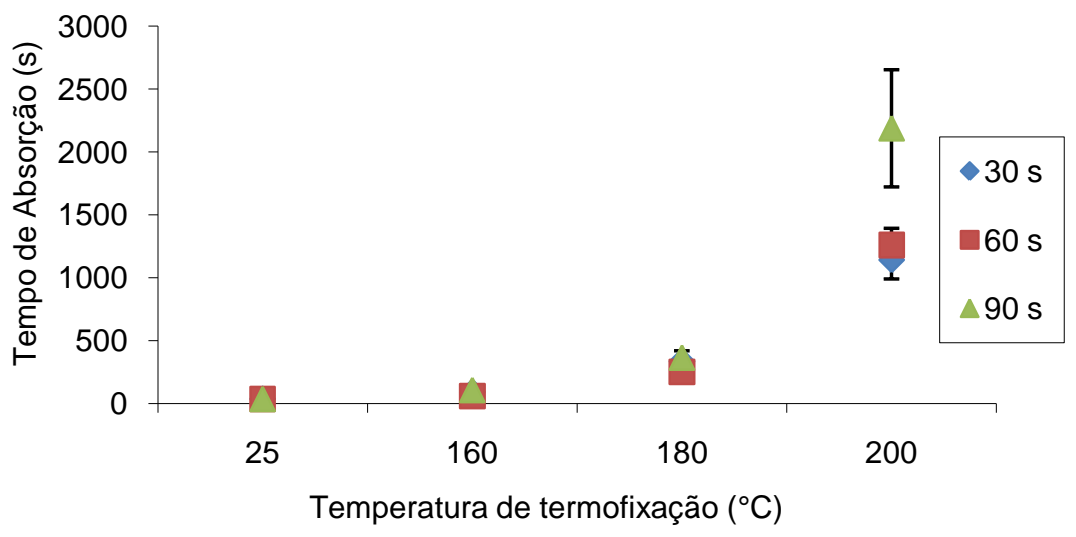

Figura 4: Tempo de absorção de uma gota de solução de corante em função do tempo de termofixação

\section{CONCLUSÕES}

- O tempo de termofixação de 30 s e temperatura de $200{ }^{\circ} \mathrm{C}$ são suficientes para boa estabilidade dimensional do tecido.

- A termofixação promove encolhimento do tecido de poliéster e esse encolhimento aumenta com aumento da temperatura do processo. O tempo de termofixação pouco influência nessa propriedade do tecido.

- A termofixação promove o aumento do índice de alongamento do tecido de poliéster e esse 
alongamento aumenta com o aumento da temperatura de termofixação. O tempo de termofixação pouco influência nessa propriedade.

- A termofixação não promove alterações consideráveis na força de ruptura do tecido de poliéster.

- A termofixação promove a diminuição da hidrofilidade do tecido de poliéster.

\section{REFERÊNCIAS}

ABRAFAS - Associação Brasileira de Produtores de Fibras Artificiais e Sintéticas. Estatísticas, ano 2012. Disponível em: http://www.abrafas.org.br, Acessado em 18/11/2013.

GARCÉN, I., MAIllo, J., CAYUELA, D., PUENTE, P., GARCÉN, J., Influência da temperatura de termofixação do poliéster (PET) na velocidade de difusão de corantes dispersos. Revista Química Têxtil, N 89, Dez 2007, pág. 26 a 36.

GEOCITIES - Análise dimensional dos tecidos. Disponível em:

http://www.geocities.ws/lcrespim/trabalhos/Alterac_dimensional.PDF. Acesso em 13/04/14.

GIORDANO, J. B., SINÉZIO, J. C.C., Estudo dos Parâmetros Tempo e temperatura na Termofixção em tecidos de Poliéster. Revista Química Têxtil, N 85, Dez 2006, pág. 44 a 54.

GUILLÉN, J. G., Nomes genéricos das fibras químicas normativas e legislação. Revista Química Têxtil, ano XXVI, nº 70, pg. 29, Mar. 2003.

LUDEWIG, H., Polyester fibres chemistry and technology, New York: Wiley-Interscience Publicacion, pg. 453, 1964.

NBR 13000 - Determinação da hidrofilide do tecido.

NBR 11912 - Determinação da resistência à tração e alongamento de tecido plano.

ODIAN,G.,Principles of polymerization, third edition, New York: Wiley-Interscience Publicacion, pg. 12-194, 1991.

RAO, Y., GREENER, J., ORTA, C. A. A., HSIAO, B. S., BLANTON, T. B.,The relationship between microstructure and toughness of biaxially oriented semicrystalline polyester films, Polymer, No 49, April 2008, pg 2507-2514.

ROUETTE, HANS-KARL. Encyclopedia of Textile Finishing. Woodhead Publishing, 2001. $3011 \mathrm{p}$.

SCHEIRS, J.,LONG, T. E., Modern Polyesters:Chemistry and Technology of Polyesters and Copolyesters. John Wiley \& Sons Ltd, England 2003. 